$\mathrm{V} \Delta \mathrm{K} 324$

ББК 66.3(0),131

DOI 10.22394/1682-2358-2018-2-125-132

A.A. Cherenev, Candidate of Sciences (Geography), researcher of the Laboratory of Georesources and Political Geography, V.B. Sochava Institute of Geography Siberian Branch of the Russian Academy of Sciences

P.L. Popov, Candidate of Sciences (Philosophy), leading engineer of the Laboratory of Theoretical Geography, V. B. Sochava Institute of Geography Siberian Branch of the Russian Academy of Sciences

\section{PROTEST \\ ELECTORAL BEHAVIOR IN THE IRKUTSK REGION AND IN IRKUTSK}

The protest electoral behavior of the population of Irkutsk region, its administrative districts, large industrial cities and municipal districts and historically developed areas of the city of Irkutsk is considered. Particular attention is paid to the territorial differentiation of the protest electoral behavior of the residents of the city of Irkutsk.

Key words and word-combinations: opposition parties, Irkutsk, the level of turnout at elections, protest electoral behavior.
A.А. ЧеренеВ, кандидат географических наук, научньй сотрудник лаборатории георесурсоведения и политической географии Института географии им. В.Б. Сочавь Сибирского отделения РАН (email: tcherenev@irigs.irk.ru)

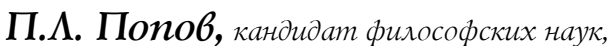
научньии сотрудник лаборатории теоретической географии Института географии им. В.Б. Сочањь Сибирского отделения РАН

(email:plp@irigs.irk.ru)

\section{ПРОТЕСТНОЕ

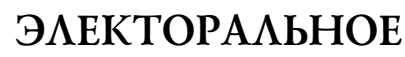 ПОВЕАЕНИЕ В ИРКУТСКЕ И ИРКУТСКОЙ ОБААСТИ}

\begin{abstract}
Аннотащия. Рассматривается протестное электоральное поведение населения Иркутской области, ее административных районов, крупных индустриальных городов и муниципальных районов и исторически сложившихся местностей г. Иркутска. Особое внимание уделяется территориальной дифференциации протестного электорального поведения жителей города Иркутска.

Ключевые слова и словосочетания: оппозиционные партии, Иркутск, уровень явки на выборы, протестное электоральное поведение.
\end{abstract}

Cos овременный этап развития российского общества требует формирования на муниципальном уровне выборных институтов вцасти на основе свободного волеизъявления граждан. Недостаток знаний о методах и приемах вовлечения населения в процессы решения вопросов местного значения определяет необходимость разработки проблем, вызванных многообразием 
социальных, экономических, этнокультурных [1, с. 401; 2, с. 277] и политических факторов развития общества. Эта проблема была поставлена еще в 1988 г. В.А. Колосовым [3] . Рассмотрим данную ситуацию в муниципальных образованиях Иркутской обкасти - региона с высоким потенциалом протестного электорального поведения. В этом отношении Иркутская область имеет немало общего с Аругими регионами Сибири и Аальнего Востока, хотя и обмадает опредеменной спецификой.

В выборах Аолжностных миџ и референдумах участвуют жители муниципальных образований, которые представляют различные соџиальные слои, отличаются разными идейными установками, относятся к определенным этническим группам, проживают на разных расстояниях от центра (регионального или федерального). Следовательно, в определенных группах населения формируются свои особые политические интересы. Необходимость и специфика исследований в области их дифференциации показана, например, в работе А.А. Карнышева, К.С. Жукова и В.Ф. Шестака [4] . ОАним из важнейших элементов электорального проџесса явцяется активизаџия сторонников того или иного политического направления в период голосования. Аیя этого необходимо знать, что представляет собой территориально мокализованное сообщество, или соџиум, как оно развивается и чем живет, как соотносится с подобными сообществами, распоможенными по соседству или в отдалении.

Насколько местное население удовлетворено работой органов власти, часто показывает протестное электоральное поведение. Необходимо уточнить значение этого термина. Обычно протестным голосованием называют электоральную подАержку, мотивированную не столько положительным отношением избирателей к соответствующему кандидату или партии, сколько отрицательным отношением к альтернативной политической силе. На наш взгляА, целесообразно использовать Аругое понятие - протестное электоральное поведение: это голосование за оппозиционные партии, голосование «против всех», низкая явка, высокий процент недействительных (испорченных бюмметеней).

Итоги избирательных кампаний 2004-2015 гг. свидетельствуют о росте неудовлетворенностинаселенияИркутскойобластиизбраннымпреАставителями правящей политической партии в регионе политическим курсом. Итогом роста недовольства работой областного руководства стала смена политической элиты в области. Уровень поддержки населением или, соответственно, жекания политических и соџиально-экономических преобразований можно проследить по протестному голосованию как на федеральном, так и на муниџипальном уровне. Следует учесть, что до 2006 г. протестное голосование, как правило, проявлялось в графе «против всех» в избирательном бюмлетене, после отмены данной графы - по субъективным оџенкам и смене руководитемей области и муниџипальных образований. Рассмотрим оба варианта на примере федеральных и муниципальных выборов 2004-2015 гг.

В Аанном исследовании разцичные типы протестного эмекторального поведения рассматриваются на разных административно-территориальных уровнях: голосование «против всех» - на уровне муниџипальных районов Ир- 
кутской области; голосование за оппозиционные партии - на региональном (некоторые субъекты РФ) и муниџипальном (крупные индустриальные города Иркутской области) и на уровне муниципальных районов и исторически сложившихся местностей г. Иркутска; явка избиратемей - на уровне муниципальных районов и исторически сложившихся местностей.

Голосование «против Всех». Отдельной графой в политических предпочтениях явмялось голосование «против всех» (в Аанном случае имеется в виду графа в избирательном бюметене), которое набирало на выборах сопоставимое с ЕР, КПРФ и АПР количество голосов, а в ряде случаев и превосходило ux (рис. 1).

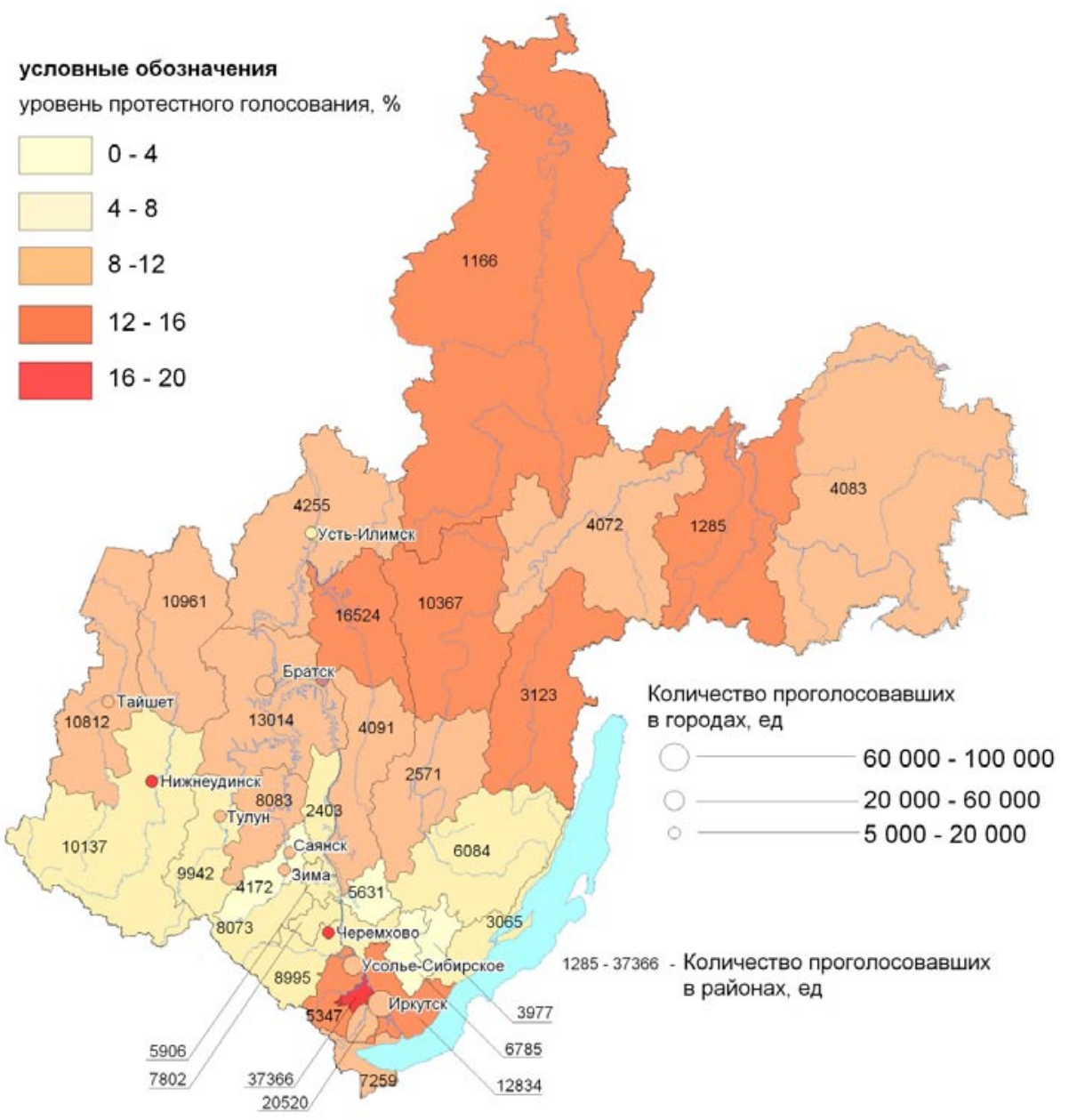

Масштаб 1: 7000000

Рис. 1. Уровень голосования «против всех» в Иркутской области и УО БАО в 2004 г. 
Графа «против всех» была введена в российское избирательное законодательство в 1991 г. и упразднена в июне 2006 г. на выборах всех уровней федеральном, региональном и местном. С 1 января 2015 г. эта графа вновь была востребована российским институтом государственного управления, но только на муниципальном уровне. Таким образом, россияне смогут голосовать против всех на выборах депутатов представительных органов местного самоуправления и выборных должностных миц местного самоуправления. Законопроект № 360863-6 «О внесении изменений в Федеральный закон "Об обеспечении конституџионных прав граждан Российской Федерации избирать и быть избранными в органы местного самоуправления» и Федеральный закон «Об основных гарантиях избирательных прав и права на участие в референдуме граждан Российской Федерации» был подписан Президентом РФ В.В. Путиным 4 июня 2014 г. и опубликован в Российской газете 6 июня 2014 г. ОАнако графа «против всех» преАусмотрена «по умолчанию» на всех муниципальных выборах, и субъект может от нее отказаться, приняв специальный закон. Соответствующий Закон Иркутской области принят Законодательным Собранием 25 ноября 2014 г., подписан губернатором 9 декабря 2014 г. (№ 148-О3 «О внесении изменений в отдельные законы Иркутской области»). Согласно Аанному Закону, жители Иркутской области по-прежнему цишены права отклонить всех кандидатов на выборные должности в органы местного самоуправления. К настоящему моменту голосование «против всех» на муниципальных выборах предусмотрено только в шести регионах - Якутии, Карелии, Белгородской, Вологодской, Калужской и Тверской областях.

В Иркутской области самый высокий уровень протестного электорального поведения наблюдается в муниципальных образованиях, где были административные конфликты, на северных и северо-западных территориях со слаборазвитой соџиальной и производственной инфраструктурой и на территориях с развитым промышленным производством и соџиальной сферой (на территориях, где существуют реальные рынки труда).

Наблюдается практически полное совпадение территорий, на которых произошло сокращение количества муниципальных образований (сельсоветов) по сравнению с 1984 г., за исключением Черемховского и Зиминского районов (рис. 2) и территорий с самым высоким уровнем протестного электорального поведения (рис. 1), что свидетельствует ухуАшении уровня жизни и указывает на отток населения из этих районов.

Голосование за оппозииионние партии. В настоящее время голосование за оппозиционные партии получимо широкое распространение в Иркутской области. Наиболее полно отображают современную политическую действительность итоги избирательных кампаний в 2010 г. (выборы мәров г. Иркутска, г. Братска, г. Усть-Илимска) и 2015 г. (выборы губернатора Иркутской области). После побеА на выборах преАставителей КПРФ (губернатор Иркутской области, мәры г. Иркутск и г. Братск) и «Справедливой России» (г. Усть-Илимск) за регионом утвердикась устойчивая репутация оппозиционной области. 


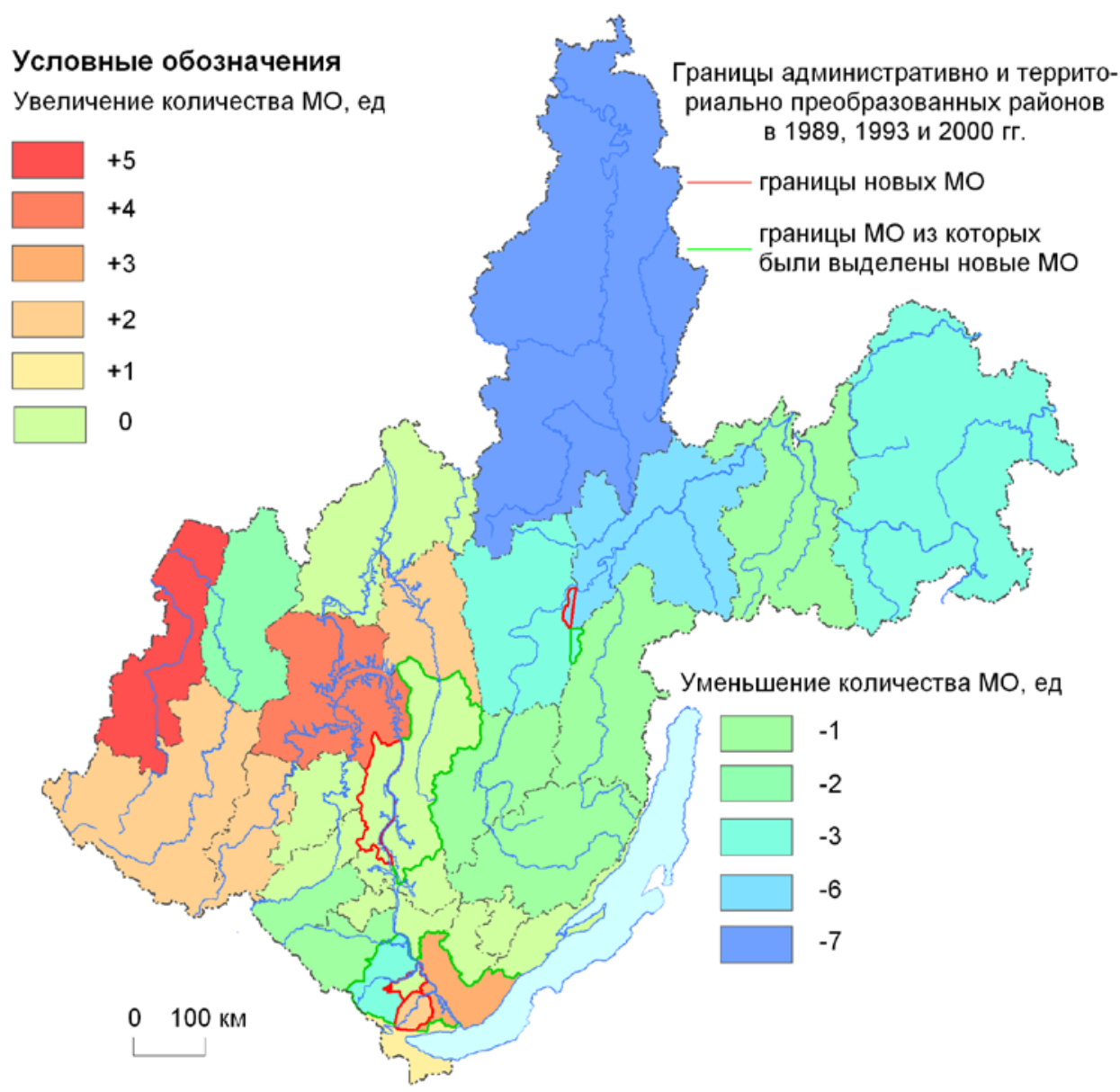

Рис. 2. Изменение административно-территориального устройства в Иркутской области в 1984-2008 гг.

В последние пятнадцать мет количество представителей «мевых» на постах руководителей субъектов РФ уменьшается. В 2003 г. губернатор Краснодарского края А.Н. Ткачев вышел из КПРФ и возглавил региональный список «ЕАиной России» на выборах в Государственную Ауму РФ. В феврале 2005 г. губернатор Курской области А.Н. Михайлов, победивший на губернаторских выборах при подаержке КПРФ в 2002 г., присоединияся к «Единой России». Весной 2005 г. у КПРФ было пять губернаторов, а к 2006 г. осталось всего цишь три: Н.В. Виноградов (Вцадимирская область), Н.К. Максюта (ВолгограАская область) и М.Б. Машковцев (Камчатская область). В 2007-2008 гг. КПРФ окончательно мишилась всех своих «красных губернаторов»: М.Б. Машковцев подал в отставку, Н.К. Максюта перешел в «Единую Россию», а Н.В. Виноградов приостановил членство в КПРФ. Процесс сокращения «оппозиционных» губернаторов был вызван мибо сменой политических взглядов, мибо окончани- 
ем срока полномочий. В 2004 г. институт прямых выборов глав субъектов РФ был упразднен до 2012 г.

По состоянию на 25 декабря 2017 г. в России один губернатор, и один исполняющий обязанности губернатора, являющиеся членами КПРФ: С.Г. Аевченко (Иркутская область) и А.Е. Клычков (Орловская область). В целом расстановка сил по политической принадлежности глав субъектов РФ выглядит следующим образом: «ЕАиная Россия» - 56 и 6 и.о. губернатора; КПРФ 1 и 1 и.о. губернатора; $\Lambda \Lambda$ ПР - 1 (Смоленская область), «Справедливая Россия» -1 и.о. губернатора (Омская область), и офиџиально беспартийных 16 и 4 и.о. губернатора.

На наш взгляА, Орловскую область нельзя назвать территорией протеста в отличие от Иркутской области, так как В.В. Потомский, занимавший вплоть Ао недавнего времени пост губернатора, был назначен на эту домжность Указом Президента РФ в 2014 г. и в сентябре того же года победим на выборах с результатом более $89 \%$, но, при этом «Единая Россия» не участвовала в выборах. Назначен на пост и.о. губернатора и А.Е. Клычков. Отметим, что Ормовская область явцяется родиной мидера второй по значимости политической силы в Российской Федерации - КПРФ, Г.А. Зюганова. Следовательно, в России можно выАелить только один регион, в котором преАставитель «мевых» (56,4\%) выиграл выборы у кандидата от «ЕАиной России» $(41,5 \%)$.

Уровни явки избирателей. На совокупности субъектов РФ, по результатам выборов в Государственную Ауму в 2016 г., сушествует высокая отриџательная корреляџия между уровнем явки избирателей и голосованием за КПРФ [5, с. 79; 6, с. 85]. В эту закономерность вписываются результаты по Иркутской обцасти и по г. Иркутску, где отмечается низкая явка и высокий уровень поддержки КПРФ. Рассмотрим электоральную ситуащию в г. Иркутске в 2010-2015 гг.

В 2010 г. на выборах мэра г. Иркутска два кандидата представцяли региональные отделения российских политических партий «ЕАиная Россия» и КПРФ и один кандидат бамлотировался в порядке самовыдвижения. На рис. 3 отражкены основные показатели итогов выборов мэра г. Иркутска. Электоральное поведение жителей г. Иркутска характеризуется низким и средним уровнем явки избиратемей и высокой степенью голосования за оппозиционные партии (рис 3). Из всех административно-территориальных единиџ и исторически сложившихся местностей только избиратели ст. Батарейная отАали большинство голосов преАставителю партии власти. По итогам голосования в г. Иркутске кандидат, поддерживаемый КПРФ, набрал 62,3\%, а кандидат от «Единой Риссии» - 27,2\%.

Политические предпочтения и средняя явка избирателей зависят от ряда экономико-географических и соџиамьно-географических характеристик. Первая - система отношений «развитые районы - депрессивные районы». В «депрессивных» районах (ст. Кая, ст. Батарейная, поселки им. Кирова, им. Горького и Жилкино, предместье Марата) отмечаются самые низкие показатели явки избирателей (значения варьируют в предеках от 18-24\%) и «оппозиџионного» (за КПРФ) голосования (37-50\%) (за искмючением п. Жилкино и ст. Кая). 


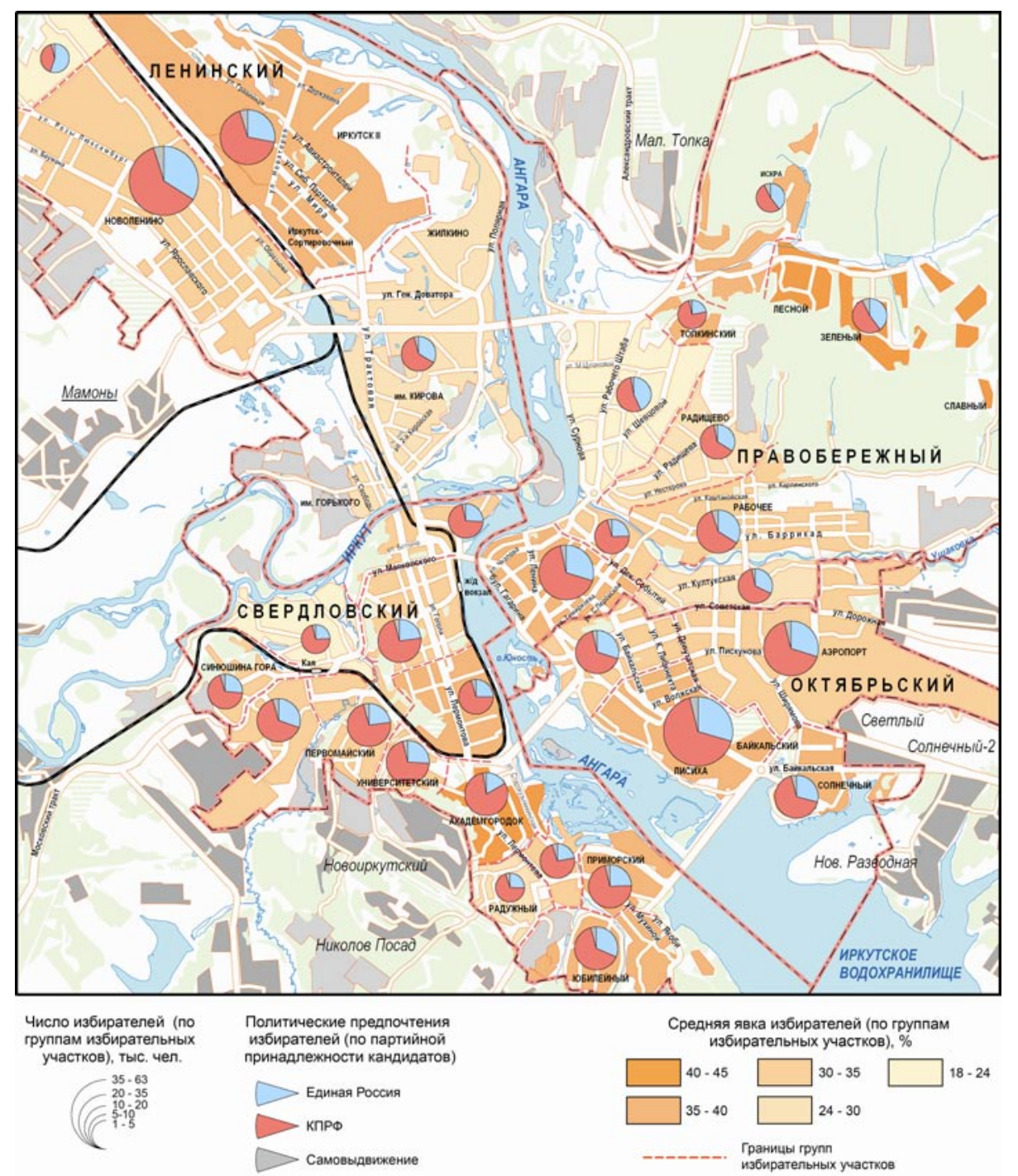

Рис. 3. Электоральная ситуация в городе Иркутске в 2010 г.

Вторая - четко выраженная территориальная дифференциация профессиональной специализации насемения районов г. Иркутска. Наибольшие значения средней явки избирателей отмечаются в районах с одной преобладающей профессиональной деятельностью местных жжителей; это микрорайон Зеленый (основная специализация населения - служба в ВС РФ), Академгородок (научная деятельность), Студгородок (научно-преподавательская и учебная деятельность), Иркутск II (проектирование, производство и послепродажное обскуживание авиаџионной техники военного и гражданского назначения). В этих районах среАняя явка избиратемей составляет $38-44,3 \%$, при средней по городу $32,6 \%$. 
Третья - степень различий по уровню материального благосостояния домохозяйств житемей г. Иркутска. В районах с многоквартирной и старой частной застройкой и с невысоким уровнем дохода жителей отмечаются наибольшие колебания в электоральном поведении населения. Так, низкая явка отмечена на ст. Кая, ст. Батарейная, в поселках им. Кирова, им. Горького и Жилкино, предместье Марата, в 3-м поселке ГЭС (18-24\%), исключением является п. Искра (37,5\%). В благополучных местах, то есть в центральных и спальных районах, а также в коттеАжных поселках явка избирателей варьирует в интервале $24-44,3 \%$.

В 2010 г. на выборах мэра г. Иркутска проголосовали: в Свердиовском округе $-36,5 \%$, Октябрьскком - 25,9\%, Аенинском - 25,5\%, Правобережном 23,6\% от общего числа насемения. На выборах 2015 г. губернатора Иркутской области жители Иркутска выразили недоверие прежнему руководителю области, отдав ему 27\% голосов; мидер Иркутского отдемения КПРФ набрам 71\% [7].

В последние восемь цет в Иркутской области наблюдаются протестные электоральные тенденции, что отражается в результатах выборов на разных административно-территориальных уровнях: повышенное голосование «против всех», низкая явка избирателей, голосование за представителей «мевых» и «мевоџентристских» политических движений Российской Федераџии. Иркутская область вписывается в закономерность, обнаруживающуюся на совокупности всех субъектов РФ: уровень явки и голосование за «мевые» партии отрицательно коррелируют межАу собой.

Высокий уровень голосования «против всех» характерен Аля территорий, на которых произошло сокращение количества мунищипальных образований (сельсоветов) по сравнению с 1984 г., за исключением Черемховского и Зиминского районов. В районах г. Иркутска, характеризующихся депрессивностью и относительно меньшей специализацией населения по роду профессиональной деятельности, уровень голосования за оппозиџионные партии повышен, а явка избиратемей понижена по сравнению со средними значениями по городу.

\section{Библиографический список}

1. Цыдыпова Л.С. Сакральные аспекты этнокультурного ландшафта баргузинской котловины // Многовекторность в развитии регионов России: ресурсы, стратегии и новые тренды: материалы XXXIII ежегодной сессии экономико-географической секции Марс. Иркутск, 2016. C. 399-407.

2. Цыдыпова Л.С. О социокультурной организации ландшафта Баргузинской котловины // Современные исследования социальных проблем. 2011. Т. 5, № 1. С. 275-277.

3. Колосов В.А. Политическая география: проблемы и методы. Л., 1988.

4. Карнышев А.Д., Жуков К.С., Шестак В.Ф. Психология и политика: вопросы теории и практики. Иркутск, 2004.

5. Попов П.Л., Сараев В.Г., Черенев А.А., Галес Д.А. Результаты выборов в ГД РФ 2016 г. и перспективы региональной поддержки кандидатов от основных политических партий на президентских выборах // Власть. Т. 25, № 8. С. 74-82.

6. Попов П.Л., Сараев В.Г., Черенев А.А. От результатов выборов в ГД РФ 2016 г. на региональном и макрорегиональном уровнях к оценке перспектив кандидатов основных партий на президентских выборах 2018 г. // Власть. 2017. Т. 25, № 11. С. 83-87.

7. Официальный сайт избирательной комиссии Иркутской области. URL: http://www.irkutsk.izbirkom.ru 